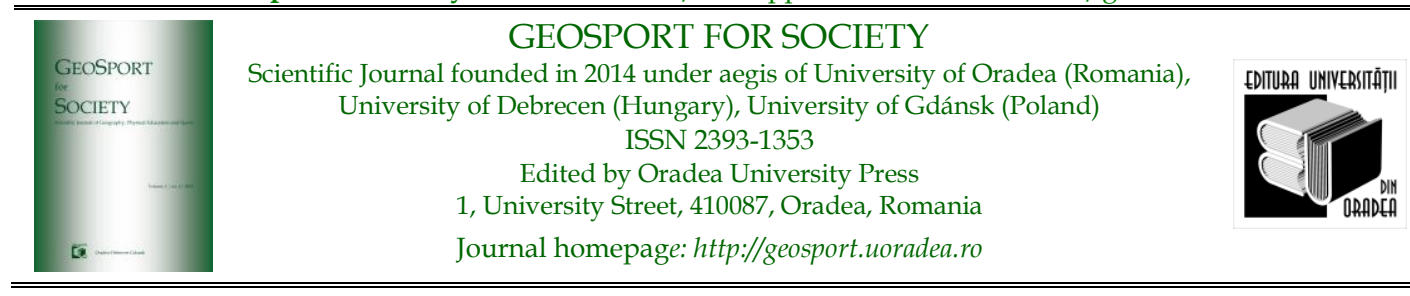

\title{
Study regarding the development process of motor qualities endurance and strength in physical education lessons during the pandemic period
}

\author{
Ioan Sabin SOPA ${ }^{1 *}$, Marcel POMOHACI ${ }^{1}$
}

1. University "Lucian Blaga" Sibiu, Faculty of Science, Department of Environmental Science, Physics, Physical Education and Sport, Dr. Ion Raţiu Street, No. 5-7, Sibiu, Romania, e-mail: sabin.sopa@ulbsibiu.ro, puiu.pomohaci@ulbsibiu.ro

* Corresponding author

Citation: Sopa, I.S., \& Pomohaci, M. (2021). Study regarding the development process of motor qualities endurance and strength in physical education lessons during the pandemic period. Geosport for Society, 15(2), 101-109. https://doi.org/10.30892/gss.1504-076

Article history: 20.09.2021; Revised: 30.09.2021; Accepted: 15.10.2021, Available online: 21.10.2021

\begin{abstract}
In 2020, everybody's life was affected by the general crisis generated by the SARS-CoV-2 Pandemic. The educational system suffered from the transition from face-to-face learning to online learning, and every activity transformed their curricula from living to online. For Physical Education activity, the process was complicated; being a principal practical activity, the online system was not such a generous field for this domain. Our study focused on the effects of the pandemic crisis on the activity of Physical Education students from Sibiu city and how teachers managed to overcome the online difficulties of teaching. As a research method, the questionnaire of opinions was used with ten items and a scale of five levels (starting from 1 that was total disagreement to 5 that was a total agreement with the affirmation). The research subjects were 35 teachers from Sibiu city (age between 22 and 45 years old, 13 females and 22 males), with different experience in the Physical Education domain. The questionnaire results showed that teachers had difficulties in the teachinglearning process during the Pandemic; students' physical condition and health were also affected. Other conclusions highlighted the idea that the endurance and strength of children were reduced due to physical inactivity. Also, the assessing process in physical education classes was complicated. The last conclusion was that most teachers consider that physical education lessons can contribute decisively to the post-pandemic health of students and can be decisive in the harmonious physical development of students and their optimal level of health.
\end{abstract}

Keywords: improving resistance, developing force, physical Education and sport

\section{Introduction}

During the past year, 2020, the worldwide suffered a big crisis generated by the SARS-CoV-2 infection, and a general pandemic was declared all over the planet. 
The pandemic infection generated many malfunctions in everyday life of the human being in all domains starting from the sanitary domain, economic, transportation, and not the last, the educational system. The classical learning process was affected by the restriction of meeting face-to-face and introducing the quarantine and the obligatorily to stay home. The whole education system had to be restructured, and teachers had to find new online solutions for continuing the learning process. Physical Education was one of the most affected from the curriculum discipline, being a predominantly practical activity in which teachers were not accustomed to using interactive electronic means.

Some scientific papers highlighted the importance of daily practicing physical Education and sports activities (Cheng et al., 2018; Engeseth et al., 2018; Tiberi and Piepoli, 2019; Tulbure et al., 2020), and also a decrease in physical activity can also affect a person's mental health, which may be experienced as unpleasant emotions such as sadness, anger, and frustration (Brooks et al., 2020). Physical activity can be positively correlated with a pandemic state. Simple physical activity can reduce the harmful effects of strict quarantine (Apriyanto et al., 2021).

Other scientific papers highlight the importance of coping with stress during the Pandemic and how physical education or sports activities could help reduce stress and anxiety (Samelko et al., 2020; Popa et al., 2020). Positive coping is associated with better mental health outcomes, while negative coping is associated with psychological problems (Mark and Smith, 2012a; Mark and Smith, 2012b). The COVID-19 outbreak poses a significant threat to public health worldwide. This mental distress has been mainly described as sleep disturbance, symptoms of anxiety and depression, post-traumatic stress disorder, decision incapacity, and even somatic symptoms (Master et al., 2020).

World Health Organization sustained the idea that School settings provide youth with critical opportunities for physical activity (PA), a key driver of positive physical, social-emotional and mental health among youth (WHO, 2020).

Following the implementation of the emergency measures, online learning has become a necessary strategy for adequate teaching in this pandemic period (Chen et al., 2020a). Physical Education in school systems should have also been adjusted to the new technologies and the classes in higher institutions that provide Education for the staff, which has raised numerous questions and problems (Batez, 2021).

Online learning is, by its nature, inequitable for school-aged youth due in part to unequal access to technology, consistent high-speed internet, adult supervision, and support, sports equipment, and physical space to participate in online physical Education (Daum, 2020; D'Augustino et al., 2021). Other inequities are presented for youth with disabilities who are mainly dependent on school physical education for PA engagement and face barriers to being physically active in home environments (Esentürk, 2020; D’Augustino et al., 2021).

If designed appropriately, online physical Education may have the potential to reduce health disparities related to inequitable opportunities for PA engagement (Draper et al., 2021; D’Augustino et al., 2021).

We would also like to emphasize the need for interdisciplinary studies, which emphasize the importance of developing proprioception (Szabo et al., 2021);, agility 
(Szabo et al., 2020; Sopa et al., 2015), balance and recovery (Szabo et al., 2018) in the process of developing motor skill strength, as well as the practice of prophylactic sports (Szabo and Magdas, 2014). Also, psychomotor assessment and biomechanical and kinematic analysis (Szabo et al., 2021) interpreted by smart (Szabo et al., 2019) means, are critical in the development of all motor qualities, not just strength and endurance.

Lately, the students' movement activities have decreased. One of the reasons is the implementation of online learning (Safruddin et al., 2020). The change from offline to online learning made various new problems, one of which is learning behavior. Moreover, the large number of lecture assignments makes students spend more time in front of the laptop (Widodo et al., 2020). This problem caused fewer students movement activities. The reduced movement activities also negatively affect the student's health (Safruddin et al., 2020).

\section{Methods of research}

The method used in our experiment was the questionnaire of opinions. The questionnaire had ten items (questions) and a gradation scale of five levels starting from 1 to 5 (with one meaning total disagreement with the affirmation and five meaning total agreement with the affirmation). The questionnaire had objectives to discover teachers' opinions from the Physical Education domain regarding the difficulties that pandemic Covid-19 produced in the learning process.

\section{Study Design and Subjects}

The questionnaire objectives were to discover the difficulties that teachers from the Physical Education domain encountered and solutions discovered. The design of the questionnaire was the following:

Table 1. The questionnaire applied to a sample of specialists in the Physical Education domain

\begin{tabular}{|c|c|c|c|c|c|}
\hline Questionnaire items & 1 & 2 & 3 & 4 & 5 \\
\hline $\begin{array}{l}\text { 1. The physical education and sports lesson represents a corresponding framework for the } \\
\text { development of the general resistance of the students }\end{array}$ & & & & & \\
\hline $\begin{array}{l}\text { 2. Increasing the level of strength of students is a primary goal in the lesson of Physical } \\
\text { Education and sports }\end{array}$ & & & & & \\
\hline $\begin{array}{l}\text { 3. The level of general resistance of students was greatly affected during the Covid-19 } \\
\text { pandemic lockdown }\end{array}$ & & & & & \\
\hline 4. The development of strength during the Pandemic was a complex process & & & & & \\
\hline $\begin{array}{l}\text { 5. Assessing motor quality, strength and endurance has been very difficult in the online } \\
\text { system due to the Pandemic }\end{array}$ & & & & & \\
\hline $\begin{array}{l}\text { 6. The level of functioning of the cardiovascular, respiratory, and exercise capacity of the } \\
\text { students was affected by the inactivity due to the pandemic period and lockdown }\end{array}$ & & & & & \\
\hline $\begin{array}{l}\text { 7. The teaching-learning process in the physical Education and sports lesson was } \\
\text { challenging during the pandemic lockdown }\end{array}$ & & & & & \\
\hline $\begin{array}{l}\text { 8. Physical inactivity in students during the pandemic period affected students' level of } \\
\text { strength and endurance }\end{array}$ & & & & & \\
\hline $\begin{array}{l}\text { 9. The lesson of Physical Education and sports can make a decisive contribution to the post- } \\
\text { pandemic health of students }\end{array}$ & & & & & \\
\hline $\begin{array}{l}\text { 10. The development of strength and endurance through the lesson of Physical Education } \\
\text { and sports contributes to the harmonious physical development of students and their } \\
\text { optimal level of health. }\end{array}$ & & & & & \\
\hline
\end{tabular}




\section{Subjects of the research}

The study focused on researching the opinions of Physical Education teachers $(n=35)$ from different schools in Sibiu city, with ages between 22 and 45 years old, 13 female and 22 males, with different professional levels and experience.

The research protocol and the purpose of the experiment were explained to all participants. The protocol was approved by the Review Board of Physical Education and Sports Department, University "Lucian Blaga" Sibiu (resolution no. $32 / 30 / 06 / 2021$ ), and all the procedures have been carried out in compliance with the Helsinki Declaration's requirements.

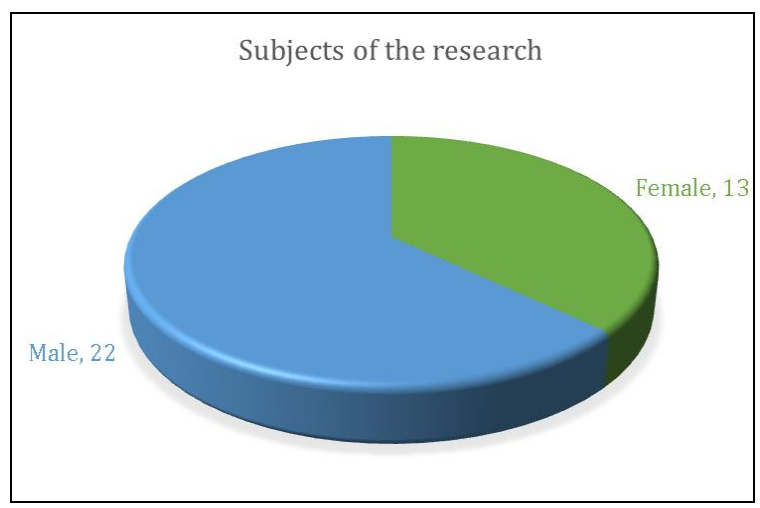

Figure 1. Subjects of the research

\section{Results}

The answers to the questionnaire were processed, and the results were presented in the following graphics. The questionnaire had ten items enquiring the effects of Pandemic over the health of children, the process of learning and teaching in Physical Education lessons.

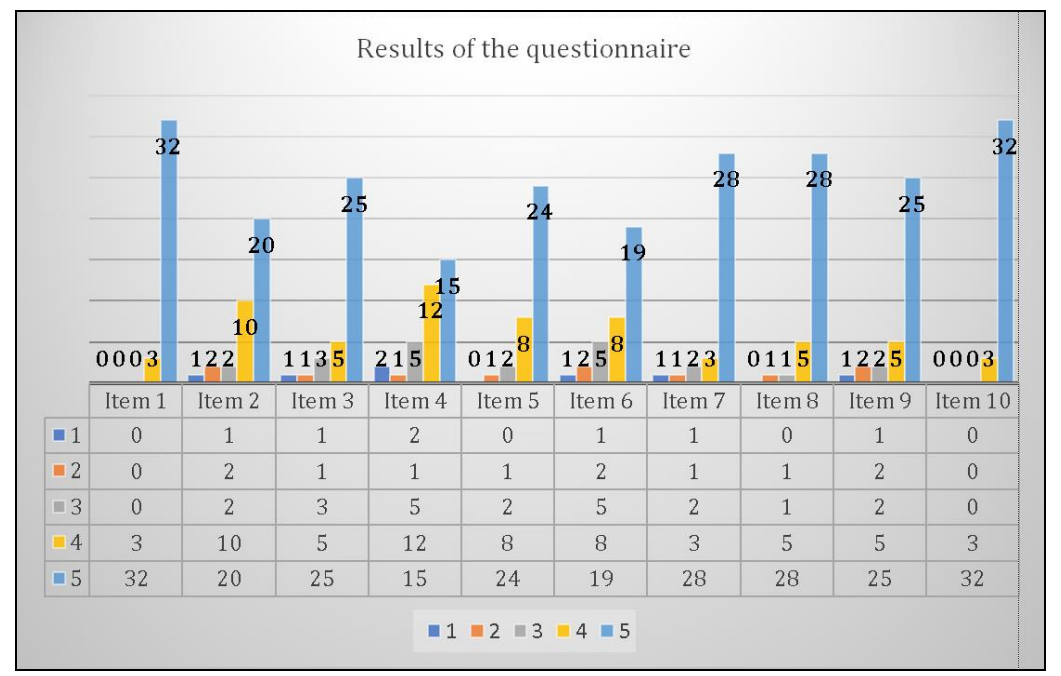

Figure 2. Results of the questionnaire 


\section{Discussion}

The situation with COVID-19 and the changes in the teaching process showed a possible window of opportunity through modern methods of communication. Moreover, this emphasizes the importance of ICT skills for Sports and Physical Education educators to significantly improve and sustain Education and solve the mentioned problems (Batez, 2021).

Conclusions of some studies (D'Augustino et al., 2021) highlighted that COVID19 also has indirect effects on minority and low-income youth, including exacerbated poverty, learning losses, poorer social-emotional and mental health, and higher school dropout rates attributable to school closures (Christakis et al., 2020; Dorn et al., 2020; Schulz et al., 2020; Benfer et al., 2021).

It is expected that immunity will increase (Chen et al., 2020b; Hall et al., 2020). Maintaining psycho-physical health in locked situations is of utmost importance, and special attention should be paid to the elderly and children (Apriyanto et al., 2021).

Although online resources are already available for educators, they are insufficient to meet current physical education teacher needs. For example, recent literature determined that "student access to online learning" and "availability of teacher resources" were substantial challenges related to online physical education instruction during the COVID-19 Pandemic (Pavlovic et al., 2021). Similarly, Mercier et al. reported that $20 \%$ of physical education teachers felt less effective teaching their students online during the Pandemic. The authors inferred that teacher response might not reflect actual learning, given that half of the sample did not use assignments or video instruction (Mercier et al., 2021).

The results of our investigation showed that Physical Education teachers encountered many difficulties in their process of teaching and learning in the sports field during the pandemic years of 2020 .

As the results of the questionnaire show the majority of teachers are in total agreement with the affirmation that physical education and sports lesson represents a corresponding framework for the development of general resistance of students, with 32 teachers, representing $91 \%$ from the total of 35 respondents, in total agreement; and three teachers, representing $9 \%$ from the total, having a good agreement with the affirmation.

From the questionnaire results, it can be observed that the majority of teachers questioned, 20 representing $57 \%$ from the total, are in total agreement with the affirmation that increasing the level of strength of students is a primary goal in the lesson of Physical Education and sports, ten respondents, representing $29 \%$ from the total, are in agreement with the affirmation, two persons, representing $6 \%$ from the total, did not agree or disagree, one person disagree and one teacher is in total disagreement.

Regarding the $3^{\text {rd }}$ item of the questionnaire, which affirmed that "the level of general resistance of students was greatly affected during the Covid-19 pandemic lockdown", we found that 25 teachers questioned, representing $71 \%$ of the total, have a firm agreement with the affirmation, five teachers agree, two did not agree or disagree, one person disagree and one person is in total disagreement with the affirmation. 
Another presumption regarding the difficulties that teachers from the Physical Education domain encountered was the development of strength during the Pandemic, 15 teachers (representing 43\% from the total) are in total agreement with the complicated process of learning and developing strength; 10 teachers (representing 29\% from the total) agree with the affirmation; 5 were not decided, two did not agree, and 1 had a total disagreement with the affirmation.

The assessment process of motor quality, strength, and endurance have been complicated in the online system due to the Pandemic that is what we discovered analyzing the results of the questionnaire, 24 teachers (representing 69\% from the total) are in total agreement, 8 teachers (representing $23 \%$ from the total) agree, only one person did not agree with the statement.

The level of functioning of the cardiovascular, respiratory, and exercise capacity of the students was affected by the inactivity due to the pandemic period, and lockdown that's what the majority of the teachers 19 (54\% from the total) questioned total agree with the affirmation; 8 teachers (23\% from the total) agree with the affirmation; 5 are not decided, and only two teachers did not agree, and one person is in total disagreement with the affirmation.

The teaching-learning process in the physical Education and sports lesson was challenging during the pandemic lockdown that is the presumption accepted by the majority of the teachers questioned 28 ( $80 \%$ from the total), three agree, two are not decided, one does not agree, and one is in total disagreement with the affirmation.

Physical inactivity in students during the pandemic period affected students' level of strength and endurance was the conclusion of the majority of teachers questioned in our experiment, 28 people (representing $80 \%$ from the total) had a total agreement with this affirmation, five teachers had agreed with the affirmation, and only one was not decided, and one did not agree with the affirmation.

Also, another conclusion of the study was that the lesson on Physical Education and sports could make a decisive contribution to the post-pandemic health of students, 25 teachers (representing 71\% of the total) had a solid agreement with this statement, five teachers agreed with the affirmation, two were not decided, two did not agree, and 1 had a strong disagreement.

In the last item of the questionnaire, the conclusions were that development of strength and endurance through the lesson of Physical Education and Sports contributes to the harmonious physical development of students and their optimal level of health, the majority of teachers 32 (representing $91 \%$ from the total) had a firm agreement and three teachers (representing 9\% from the total) agreed with this statement, none disagreed the statement.

\section{Conclusions}

The Pandemic Covid 19 certainly changed the teaching-learning habits for both sides teachers and students; the standard curricula had to be adapted to the online activity conditions, changing and affecting all learning systems. Physical Education, a principal practical activity, was undoubtedly affected by the impossibility of practicing it on good gyms or fields, with particular objects, making 
it sometimes an impossible mission. Teachers managed to find a way to adapt the curricula of Physical Education to online activity, and the process of teaching and learning somewhat survived.

The conclusions of our investigation highlight the low efficiency of online teaching and learning in the Physical Education activity during the pandemic Covid 19 period. The majority of teachers enquired had a strong agreement that the physical education classes represent the perfect framework for developing general resistance and has as main goal developing children's strength. Also, most teachers agreed that the Pandemic Covid-19 greatly affected children's general health and physical condition because they were unable to do physical activity proprietly, physical strength and resistance levels were also affected by poor options for physical activity at home.

Other conclusions of the questionnaire were that assessing the motor development was difficult to impossible in the online system with many difficulties and finding adequate teaching methods.

The level of functional development, cardiovascular and respiratory system was affected due to the Pandemic; children's physical activity was reduced close to none, affecting their strength and endurance.

Positive conclusions were also found in questioning the teachers; the majority of the respondents agreed that physical education lessons could contribute decisively to the post-pandemic health of students and can be decisive in the harmonious physical development of students and their optimal level of health.

\section{References}

Apriyanto, R. \& Adi, S. (2021). Effectivness of online learning and physical activities study in physical Education during Pandemic Covid 19. Kinestetik: Jurnal Ilmiah Pendidikan Jasmani, 5(1), 64-70. https://doi.org/10.33369/ik.v5i1.14264

Batez, M. (2021). ICT skills of university students from the Faculty of Sport and Physical Education during the COVID-19 Pandemic. Sustainability, 13, 1711. https://doi.org/10.3390/su13041711

Benfer, E.A., Vlahov, D., Long, M.Y., Walker-Wells, E., Pottenger, J.L.Jr., \& Gonsalves, G. (2021). Eviction, health inequity, and the spread of COVID-19: housing policy as a primary pandemic mitigation strategy. J. Urban Health, 98, 1-12. https://doi.org/10.1007/s11524-020-00502-1

Brooks, S., Webster, R., Smith, L., Woodland, L., Wessely, S., Greenberg, N., \& Rubin, G. (2020). The psychological impact of quarantine and how to reduce it: rapid review of the evidence. The Lancet, 395. https://doi.org/10.1016/S0140-6736(20)30460-8

Chen, P., Mao, L., Nassis, G.P., Harmer, P., Ainsworth, B.E., \& Li, F. (2020a). Wuhan coronavirus (2019): The need to maintain regular physical activity while taking precautions. Journal of Sport and Health Science, 9(2), 103-104. https://doi.org/10.1016/i.jshs.2020.02.001

Chen, T., Peng, L., Jing, B., Wu, C., Yang, J., Cong, G. (2020b). The impact of the COVID-19 Pandemic on user experience with online education platforms in China. Sustainability, 12, 7329. https://doi.org/10.3390/su12187329

Cheng, W., Zhang, Z., Cheng, W., Yang, C., Diao, L., \& Liu, W. (2018). Associations of leisure-time physical activity with cardiovascular mortality: A systematic review and meta-analysis of 44 prospective cohort studies. European Journal of Preventive Cardiology, 25(17), 1864-1872. https://doi.org/10.1177/2047487318795194

Christakis, D.A., Van Cleve, W., \& Zimmerman, F.J. (2020). Estimation of US children's educational attainment and years of life lost associated with primary school closures during the coronavirus disease 2019 pandemic. JAMA network open, 3(11), e2028786-e2028786. 
D’Augustino, E.M., Urtel, M., Webster, C.A., McMullen, J., \& Culp, B. (2021). Virtual Physical Education During Covid-19: Exploring future directions for equitable online leargning tools. Frontiers in Sports and Active Living, 3, 1-6. https://doi.org/10.3389/fspor.2021.716566

Daum, D.N. (2020). Thinking about hybrid or online learning in physical Education? Start here! JOPERD, 91, 42-44. https://doi.org/10.1080/07303084.2020.1683387

Dorn, F., Khailaie, S., Stoeckli, M., Sebastian C., Binder, S.C., Lange, B., Lautenbacher, S., Peichl, A., Vanella, P., Wollmershäuser, T., Fuest, C., \& Meyer-Hermann, M. (2020). The Common Interests of Health Protection and the Economy: Evidence from Scenario Calculations of COVID-19 Containment Policies. BMJ Yale. https://doi.org/10.1101/2020.08.14.20175224

Draper, C.E., Milton, K., \& Schipperijn, J. (2021). COVID-19 and physical activity: how can we build back better? J Phys Act Health, 18, 149-150. https://doi.org/10.1123/ipah.2021-0037

Engeseth, K., Prestgaard, E.E., Mariampillai, J.E., Grundvold, I., Liestol, K., Kjeldsen, S.E., ... \& Skretteberg, P.T. (2018). Physical fitness is a modifiable predictor of early cardiovascular death: A 35-year follow-up study of 2014 healthy middle-aged men. European journal of preventive cardiology, 25(15), 1655-1663. https://doi.org/10.1177/2047487318793459

Esentürk, O.K. (2020). Parents' perceptions on physical activity for their children with autism spectrum disorders during the novel Coronavirus outbreak. Int. J. Dev. Disabil, 1-12.

Hall, G., Laddu, D., Phillips, S., Lavie, C., \& Arena, R. (2020). A tale of two pandemics: How will COVID-19 and global trends in physical inactivity and sedentary behavior affect one another? Progress in Cardiovascular Diseases, 64, 108. https://doi.org/10.1016/j.pcad.2020.04.005

Mark, G., \& Smith, A.P. (2012a) Effects of occupational stress, job characteristics, coping, and attributional style on the mental health and job satisfaction of university employees. Anxiety, Stress, and Coping, 25(1), 63-78. https://doi.org/10.1080/10615806.2010.548088

Mark, G., \& Smith, A.P. (2012b). Occupational stress, job characteristics, coping, and the mental health of nurses. British Journal of Health Psychology, 17(3), 505-521. https://doi.org/10.1111/j.2044$\underline{8287.2011 .02051 . x}$

Master, A.N., Su, X., Zhang, S., Guan, W., \& Li, J. (2020). Psychological impact of COVID-19 outbreaks on frontline nurses: A cross-sectional survey study. Journal of Clinical Nursing, 29(21/22), 4217-4226.

Mercier, K., Centeio, E., Garn, A., Erwin, H., Marttinen, R., \& Foley, J. (2021). Physical education teachers' experiences with remote instruction during the initial phase of the COVID-19 Pandemic. J. Teach. Phys. Educ. 40, 337-342. https://doi.org/10.1123/itpe.2020-0272

Pavlovic, A., DeFina, L. F., Natale, B. L., Thiele, S. E., Walker, T. J., Craig, D. W., ... \& Kohl, H. W. (2021). Keeping children healthy during and after COVID-19 pandemic: meeting youth physical activity needs. BMC public health, 21(1), 1-8. https://doi.org/10.1186/s12889-021-10545-x

Popa, C. O., Schenk, A., Rus, A., Szasz, S., Suciu, N., Szabo, D. A., \& Cojocaru, C. (2020). The Role of Acceptance and Planning in Stress Management for Medical Students. Acta Marisiensis-Seria Medica, 66(3), 101-105.

Safruddin, S., Nasaruddin, N., Widodo, A., Sobri, M., \& Radiusman, R. (2020). Students' basic movement skills in Physical Education during the online learning. Advances in Social Science, Education and Humanities Research, 556, 314-317.

Samelko, A., Szczypinska, M., \& Guszkowska, M. (2020). Styles of coping with stress presented by female and male students of Physical Education during the Pandemic. International Journal of Physical Education, Fitness and Sports, 9(4), 85-90. https://doi.org/10.34256/ijpefs2049

Schulz, A.J., Mehdipanah, R., Chatters, L.M., Reyes, A.G., Neblett, E.W. Jr., \& Israel, B.A. (2020). Moving health education and behavior upstream: lessons from COVID-19 for addressing structural drivers of health inequities. Health Educ. Behav. 47, 519-524.

Sopa, I.S., \& Szabo, D.A. (2015). Testing agility and balance in volleyball game. Discobolul Phys Educ Sport Kinetother J, 11(41), 167-174.

Szabo, D.A., Magdaş, L. (2014). Increasing the defensive efficiency in volleyball using the statistical program "Click\&Scout". Conference proceedings of eLearning and Software for Education (eLSE), Issue 1, p. 223-228.

Szabo, D.A., Neagu, N., Popoviciu, H.V., Szasz, S., Şopterean, T.A., \& Munteanu, R.M. (2020). The benefits of the TECAR therapy in flexion recovery after revision of the anterior cruciate ligament (ACL). Timisoara Physical Education and Rehabilitation Journal, 13(25), 27-35. http://dx.doi.org/10.2478/tperj-2020-0013 
Szabo, D.A., Sopa, I.S., Stoica, R.S., \& Ivănescu, A. (2018). The effectiveness of physiotherapeutic treatment in the recovery of the collateral ligament lesion. Discobolul - Physical Education, Sport and Kinetotherapy Journal, 14(52), 16-24.

Szabo, D.A., Neagu, A., Ilieș, A., \& Ardelean, M. (2021). Linear kinematic analysis of cinematic biomechanics in semi-squat knee flexion: a case study. Geosport for Society, 14(1), 56-66. https://doi.org/10.30892/gss.1406-073

Szabo, D. A., Neagu, N., Teodorescu, S., Panait, C. M., \& Sopa, I. S. (2021). Study on the Influence of Proprioceptive Control versus Visual Control on Reaction Speed, Hand Coordination, and Lower Limb Balance in Young Students 14-15 Years Old. International Journal of Environmental Research and Public Health, 18(19), 10356. https://doi.org/10.3390/ijerph181910356

Tiberi, M., \& Piepoli, M. F. (2019). Regular physical activity only associated with low sedentary time increases survival in post myocardial infarction patient. European Journal of Preventive Cardiology, 26(1), 94-96. https://doi.org/10.1177/2047487318811180

Tulbure, R. E., Neagu, N., \& Szabo, D. A. (2020). Comparative study on the development of the motor skill (strength) through the circuit method versus dynamic games in physical education classes. Health, Sports \& Rehabilitation Medicine, 21(4), 223-230. $\frac{\text { https://doi.org/10.26659/pm3.2020.21.4.223 }}{\text { (2020). Prevalence of Insufficient Physical Activity. Available online at: }}$

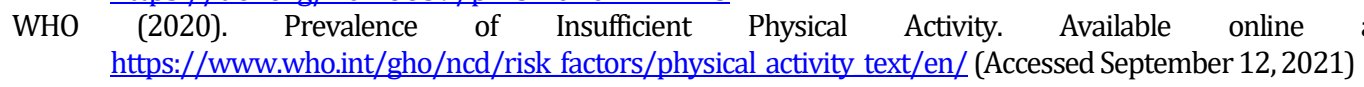

Widodo, A., Nursaptini, N., Novitasari, S., Sutisna, D. (2020). From face-to-face learning to web base learning: How are student readiness? Premium Educandum: Journal Pendidikan Dasar dan Pembelajaran, 10(2), 149-160. https://doi.org/10.25273/pe.v10i2.6801 